\title{
The Potential Incorporation of Biochar into a Char-Water Fuel - Study of Chemical and Physical Properties
}

\author{
J. P. Pillai, G. J. Griffin, and M. Pannirselvam
}

\begin{abstract}
Biochar has the potential to be used for a wide range of applications. One of these includes utilisation as a char-water fuel, with the aim of substituting less sustainable fuels in the future. This paper reports the chemical and physical properties of biochar produced from sugarcane bagasse for use as a char-water fuel. Sugarcane bagasse was pre-treated with diammonium phosphate (DAP) and pyrolysed to increase the yield of biochar. An untreated sample of bagasse was also converted to biochar for comparison. The treated samples were formulated into char-water fuel and analysed for rheological behaviour. Viscosities were comparable to that reported for coal-water slurry fuels and, in some cases, other biological by-products (i.e. biooils), but were higher than diesel or gasoline. Thermal gravimetric analysis (TGA) and particle size distribution were conducted on the char samples and the energy content was measured using bomb calorimetry. The energy content of the char-water fuel would be similar to that of coal-water fuels if beneficiation of the biochar to remove ash components can be performed.
\end{abstract}

Index Terms-Biochar, pyrolysis, char-water fuel, bagasse.

\section{INTRODUCTION}

Increasing global concerns regarding sustainable practice and environmental protection has seen a growth in research on renewable energies. With a heavy reliance still placed on fossil fuels for energy, there are many studies analysing potential substitutes, including generating biofuel as a product of biochar. Biochar is a carbon-rich material which originates from biomass being heated under oxygen-deprived conditions [1]. The properties of biochar allow for it to have several applications such as soil fertilizers, gas adsorbents and biofuels [2]. However, research on the suitability of these applications is still fairly recent, and more research is required to better understand this material.

Sugar cane bagasse (SCB) is one of the most common feedstocks for biochar, and is also considered to be the world's largest source of lignocellulosic agricultural residue [3]. SCB is produced following the extraction of sugar juice during milling. Some sugar mills use SCB as energy generators, however this is often converted at low efficiencies (approximately 26\%) and poses some health risks regarding dust and ash production [4]. SCB represents a promising feedstock for biochar as it is a waste which, potentially, can be transformed to a saleable product on-site.

Manuscript received September 15, 2017; revised March 2, 2018.

J. P. Pillai is with the School of Engineering, RMIT University, Melbourne, Australia.

G. J. Griffin and M. Pannirselvam are with RMIT University, Melbourne, Australia (e-mail: muthu.pannirselvam@rmit.edu.au).
Pyrolysis of biomass to produce biochar can be described as thermal degradation which is carried out either in a completely oxygen-deprived environment, or at such a low rate so that gasification does not occur [5]. Research has been undertaken to analyse how pyrolysis of SCB yields fuel gases with the literature showing that the pyrolysis of SCB to biochar, biooils and gases were much more efficient (in terms of energy recovery of pyrolysis product) than the fermentation of SCB into ethanol [6]. Slow pyrolysis, usually using a temperature range between 350 and $800^{\circ} \mathrm{C}$ at slow heating rates (i.e. between 10 to $50^{\circ} \mathrm{C} / \mathrm{min}$ ) has been shown to produce a high-carbon, energy-dense solid char product which optimises char yield [1, [2], [7]. It has been shown that chemical pre-treatment of SCB can further enhance yields of char [8, [9].

Reports on the incorporation of biochar into a liquid media to form a stable suspended solid involves crushing the biochar to a particle size less than 70 micron, followed by addition to water with a suitable surfactant [10], [11] to seek a stable suspension. However, studies are sparse and conditions in which stable suspension are produced has have been elusive. Many more studies have been conducted where coal particles are suspended in water for use as a liquid fuel. Slurry fuels can have a significant advantage compared to using solid coal particles as water reduces flame temperature and $\mathrm{NO}_{\mathrm{x}}$ emission with little energy loss to water vaporisation; the fuel is easily stored in tanks and pumped, and; there is no risk of dust explosions [12]. The main impediments to implementation of such fuels in power station applications is producing a high char content of the slurry with high energy content without a concomitant high viscosity that causes difficulty in the pumping and atomisation of the fuel [13]. Early studies on coal-water fuels with very fine particle size $(<5$ micron $)$ and low ash $(<1 \%)$ indicated suitability as a locomotive diesel fuel [14] but a commercial use of such a fuel has not arisen, and with the loss of favour of coal as a fuel this is unlikely to ever occur.

The aim of the research reported here was to measure the chemical and physical properties of biochar produced from chemically treated SCB for use as a char-water fuel and to compare these with other liquid fuels commonly used in transportation and stationary engine operations.

\section{MATERIALS AND MethodS}

\section{A. Preparation of Biochar and Char-Water Fuel}

Biochar was produced from SCB. The SCB was sourced from a retail store and was not washed or cleaned prior to treatment. Samples $(100 \mathrm{~g})$ of crushed (particle size less than 
$1 \mathrm{~mm})$ SCB were immersed in $600 \mathrm{ml}$ of aqueous diammonium phosphate (DAP), using concentrations of $0.01 \mathrm{M}, 0.1 \mathrm{M}$ or $1 \mathrm{M}$. The treated samples were air-dried and then pyrolysed in a tube furnace. The tube furnace was operated with a constant flow of nitrogen and samples were heated from ambient temperature at $10^{\circ} \mathrm{C} / \mathrm{min}$ until reaching a temperature of $400^{\circ} \mathrm{C}$, and then maintained at that temperature for 30 minutes after which the samples were cooled to ambient temperature. After pyrolysis, the biochar was re-crushed and sieved to recover all material of nominal particle diameter under $70 \mu \mathrm{m}$.

To prepare the char-water fuel an aqueous solution containing $4 \mathrm{wt} \%$ sodium dodecylbenzene-sulfonate (SDS) was manually mixed with the biochar particles to yield a suspension of $50 \mathrm{wt} \%$ biochar.

\section{B. Characterisation of Biochar and Char-Water Fuel}

Samples of biochar and untreated bagasse were analysed using a Perkin-Elmer STA 600 thermal gravimetric analyser to measure the ash, fixed carbon, volatile fraction and moisture content. Samples of between 10 and $30 \mathrm{mg}$ were heated from ambient temperature to $110^{\circ} \mathrm{C}$, under a nitrogen flow of $20 \mathrm{ml} / \mathrm{min}$, and maintained at this temperature for 10 minutes to determine moisture content. The samples were then heated at a rate of $20^{\circ} \mathrm{C}$ to $800^{\circ} \mathrm{C}$ to determine the volatile fraction. Finally, the gas environment of the sample was switched from nitrogen to air and maintained at $800^{\circ} \mathrm{C}$ for 10 minutes to oxidise any remaining organic components and thus determine the fixed carbon and ash content of the samples.

The calorific value of the biochar was measured using a Parr Bomb Calorimeter 6400. The particle size distribution was measured using a Malvern Mastersizer 3000. Measurements were conducted in triplicate.

The rheological properties of the char-water fuel were measured using a TA DHR3 rheometer. All tests were conducted at $25^{\circ} \mathrm{C}$ with an initial shear rate of $0.01 \mathrm{~s}-1$ to a final shear rate of $500 \mathrm{~s}-1$. The tests were conducted over a 10 minute duration.

\section{RESULTS AND DISCUSSION}

\section{A. Particle Size Distribution of Biochar Particles}

\begin{tabular}{lccc}
\multicolumn{4}{c}{ TABLE I: PARTICLE SIZE DISTRIBUTION OF CRUSHED BIOCHARS } \\
\hline \hline & $\begin{array}{l}\mathrm{D}_{\mathrm{x}} 10 \\
(\mu \mathrm{m})\end{array}$ & $\begin{array}{l}\mathrm{D}_{\mathrm{x}} 50 \\
(\mu \mathrm{m})\end{array}$ & $\begin{array}{l}\mathrm{D}_{\mathrm{x}} 90 \\
(\mu \mathrm{m})\end{array}$ \\
\hline Untreated Biochar & $10.3 \pm 0.3$ & $69.8 \pm 2.0$ & $431 \pm 40$ \\
0.01M DAP Biochar & $1.54 \pm 0.02$ & $5.80 \pm 0.07$ & $22.9 \pm 2.0$ \\
0.1M DAP Biochar & $1.07 \pm 0.01$ & $4.67 \pm 0.04$ & $18.1 \pm 0.8$ \\
1.0M DAP Biochar & $1.59 \pm 0.06$ & $7.50 \pm 0.27$ & $36.9 \pm 2.5$ \\
\hline \hline
\end{tabular}

Table I shows a table of the particle sizes of the crushed biochar after no treatment or treatment with DAP followed by pyrolysis. With the exception of the untreated biochar, crushed samples had similar size distributions with particles at the $90 \%$ percentile well below $70 \mu \mathrm{m}$. Note that coal trialled for coal-water fuels are usually milled to a mass medium diameter (mmd) of 30 to $50 \mu \mathrm{m}$ [12]. The relative large particle size of the biochar produced from untreated bagasse was attributed to agglomeration of the particles during the tests.

\section{B. TGA of Bagasse and Biochar}

Fig. 1 shows the mass loss of samples of bagasse and biochar when subjected to the controlled heating of TGA. Note that the residual mass fraction excludes the ash content of the materials. Tables II shows the proximate analysis of the bagasse and biochar based upon the data provided by the TGA. In all cases, the pyrolysis of bagasse leads to a higher mass fraction of fixed carbon and ash. The original bagasse sample was unwashed so it retained soil from harvesting and this would account for the very high ash content of the bagasse. When pyrolysed this ash component was retained while a significant fraction of the volatile component was lost (note that over $90 \%$ of the organic component of untreated bagasse was volatile) hence the ash component of the resulting biochar was very high (i.e. above 50\%). Coal-water fuels typically undergo beneficiation to reduce ash content to below about 4\% [12] so as to improve combustion characteristics and ameliorate fouling issues in the furnaces and boilers. It can be seen that the ash content of the biochar was the lowest for that produced by treating the bagasse with 0.01M DAP, with the ash content increasing as the DAP concentration used for treatment increased. The treatment process for the bagasse prior to pyrolysis has the effect of washing the bagasse thus removing soil from the bagasse, while adding new inorganic components in the form of the additives. During pyrolysis, ammonia gas is evolved from the biochar but the phosphate species tend to be retained in the biochar. Thus when higher DAP concentrations are used for treating the bagasse, the ash content increases. The ratio of fixed carbon to volatile components decreased for the treated biochars as the concentration of DAP increased. It has been shown in previous research [8] that at high DAP concentrations, the phosphate species react to form polymeric compounds in the biochar which degrades at temperatures of around $600^{\circ} \mathrm{C}$ thus contributing to the volatile fraction of the material.

\begin{tabular}{lccc}
\multicolumn{4}{c}{ TABLE II: PROXIMATE ANALYSIS AND CALORIFIC VALUE OF MATERIALS } \\
\hline \hline & $\begin{array}{c}\text { Moisture } \\
(\%)\end{array}$ & $\begin{array}{c}\text { Volatile } \\
(\% \mathrm{db})\end{array}$ & $\begin{array}{c}\text { Fixed Carbon } \\
(\% \mathrm{db})\end{array}$ \\
\hline Untreated Bagasse & 2.8 & 75.0 & 1.0 \\
Untreated Biochar & 5.9 & 18.3 & 15.9 \\
0.01M DAP Biochar & 3.9 & 21.3 & 27.7 \\
0.1M DAP Biochar & 3.5 & 18.3 & 17.4 \\
1.0M DAP Biochar & 6.4 & 21.4 & 13.7 \\
\hline & Ash & Calorific value* & Calorific value** \\
& $(\% \mathrm{db})$ & $(\mathrm{MJ} / \mathrm{kg})$ & 24.3 \\
\hline Untreated Bagasse & 24.0 & 17.9 & 46.7 \\
Untreated Biochar & 65.9 & 15.0 & 47.1 \\
0.01M DAP Biochar & 51.0 & 22.2 & 55.0 \\
0.1M DAP Biochar & 64.4 & 18.9 & 33.4 \\
1.0M DAP Biochar & 64.9 & 11.0 & \\
\hline \hline
\end{tabular}

* - Gross value. ** - On a moisture and ash free basis

\section{Rheology Properties of Char-Water Fuel}

Char-water fuels composed of $50 \%$ biochar treated with 
DAP were produced and rheological properties tested. Figures 2 and 3 shows the shear rate - shear stress performance of the fuels and the apparent viscosity vs shear rate of the fuels respectively. The figures show that all fuels exhibit pseudoplastic behaviour which agrees with previous reported research ([11], [15]. The fuels produced using biochars treated with $0.01 \mathrm{M}$ and $0.1 \mathrm{M}$ DAP exhibited very similar apparent viscosities ranging from $10 \mathrm{~Pa}$.s at low shear rates to $0.3 \mathrm{~Pa} . \mathrm{s}$ at higher shear rates. However, the char-water fuel with biochar treated with 1M DAP exhibited much lower viscosities of around 0.3 Pa.s at low shear rates and $0.02 \mathrm{~Pa}$.s at high shear rates. It was observed that, for the 0.01M DAP and 0.1M DAP treated samples, some particle settling and agglomeration had occurred which may explain the higher viscosities.

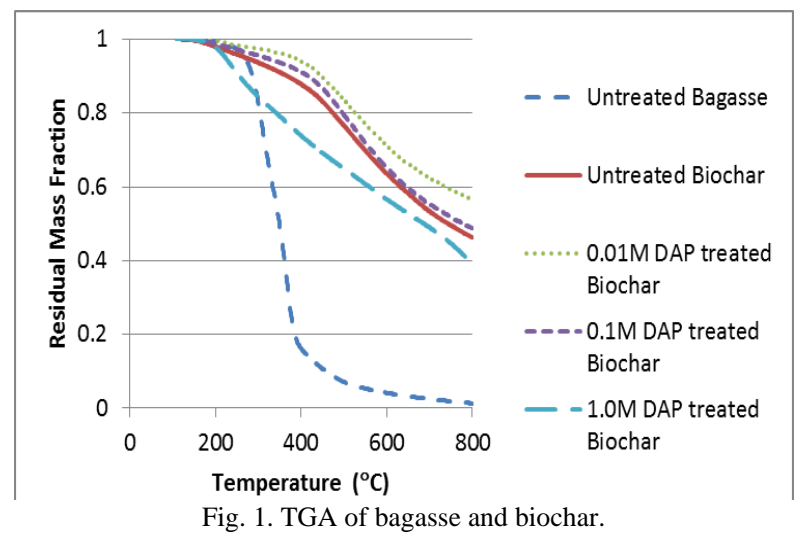

The viscosities of the fuel are encouraging when compared to coal-water studies. At a loading of $50 \%$ coal, coal-water slurries have a viscosity in the range of $0.5-1.0 \mathrm{~Pa} . \mathrm{s}$ [16]. Moreover, the viscosities at the lower end are similar to that measured for bio-oil (0.01 Pa.s). However, the viscosity is much higher than that measured for truck diesel (0.0021 Pa.s) or petroleum (0.00012 Pa.s) [17]. Reduction of the char-water slurry viscosity is plausible with the addition of suitable additives [16]. Low viscosity is an important characteristic of a char-water fuel as it is a key factor which impacts the quality of combustion. Fuels with high viscosities usually result in improper atomisation, which then leads to incomplete combustion. Ignition or combustion cannot be achieved without efficient atomisation, which is needed for the complete mixing of fuel and heated air ([12]).

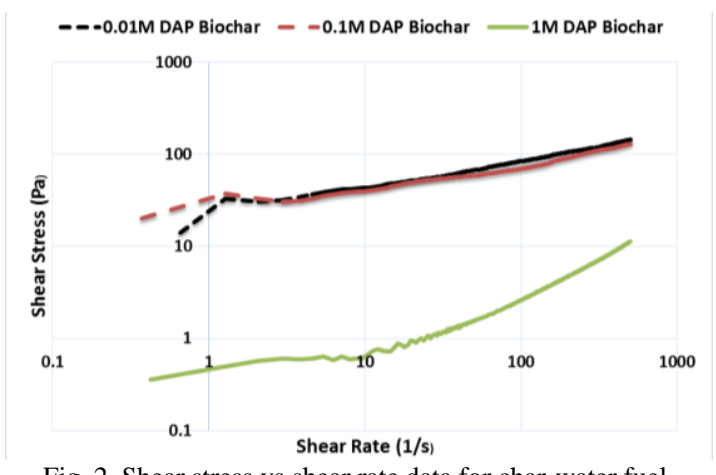

Fig. 2. Shear stress vs shear rate data for char-water fuel.

\section{CONCLUSIONS}

The tests on the pyrolysis of bagasse to produce a char for incorporation into a char-water fuel shows clear potential for producing a fuel of similar characteristics as that of coal-water fuels if the ash content of the biochar can be reduced to acceptable values. The tests chars produced have very high ash values (greater than 50\%) indicating the need for the inclusion of beneficiation to remove significant quantities of the inorganic fractions. Calorific values of $47.1 \mathrm{~kJ} / \mathrm{kg}$ are achievable if the ash may be removed from the biochar. The fuels produced would then be suitable for use as a substitute for feeds to stationary power sources (eg. power stations) or for heavy oils (eg. large ocean vessels). However, even with beneficiation the viscosity and calorific content of the char-water fuels are unsuitable as a substitute for conventional automobile or truck fuels without significant technological improvement.

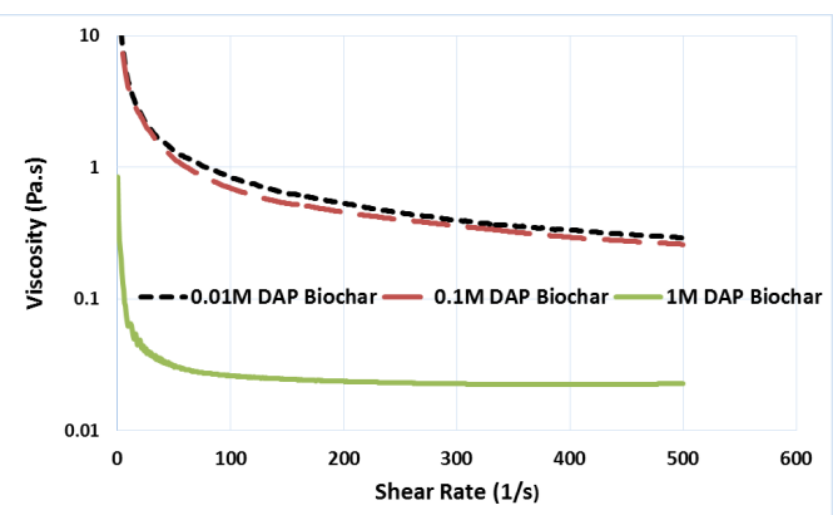

Fig. 3. Shear stress vs shear rate data for char-water fuel.

\section{REFERENCES}

[1] D. E. Brewer and R. C. Brown, "Biochar," Comprehensive Renewable Energy, vol. 5, pp. 357-384, 2012.

[2] G. K. Ellem and C. J. Mulligan, "Biomass char as a fuel for internal combustion engines," Asia-Pacific Journal of Chemical Engineering, vol. 7, no. 5), pp. 769-776, 2012.

[3] C. O. Tuck, E. Pérez, I. T. Horváth, R. A. Sheldon, and M. Poliakoff, "Valorization of biomass: Deriving more value from waste," Science, vol. 337, pp. 695-699, 2012.

[4] M. Garcia-Perez, A. Chaala, and C. Roy, "Vacuum pyrolysis of sugarcane bagasse," Journal of Analytical and Applied Pyrolysis, vol. 65, no. 2, pp. 111-136, 2002.

[5] A. V. Bridgwater and G. Grassi, Biomass Pyrolysis Liquids Upgrading And Utilisation, Elsevier Science Publishers, Essex, England, 1991.

[6] N. H. Leibbrandt, J. H. Knoetze, and J. F. Görgen, "Comparing biological and thermochemical processing of sugarcane bagasse: An energy balance perspective," Biomass and Bioenergy, vol. 35, no. 5, pp. 2117-2126, 2011.

[7] T. J. Hugo. (March 2017). Pyrolysis of Sugarcane Bagasse. University of Stellenbosch. [Online]. Available: http://www.crses.sun.ac.za/files/research/completed-research/bio_ener gy/thomas_hugo.pdf

[8] G. J. Griffin, "The effect of fire retardants on combustion and pyrolysis of sugar-cane bagasse," Bioresource Technology, vol. 102, pp. 8199-8204, 2011.

[9] G. J. Griffin, C. K. Tan, L. K. Ho, and M. Pannirselvam, "Conversion of bagasse to char-water fuel by pyrolysis," WIT Transactions on Ecology and the Environment, vol. 195, pp. 39-49, 2015.

[10] R. Chen, M. Wilson, Y. K. Leong, P. Bryant, H. Yang, and D. K. Zhang, "Preparation and rheology of biochar, lignite char and coal slurry fuels," Fuel, vol. 90, pp. 1689-1695, 2011.

[11] P. Shivaram, Y. K. Leong, H. Yang, and D. K. Zhang, "Flow and yield stress behaviour of ultrafine Malle biochar slurry fuels: The effect of particle size distribution and additives," Fuel, vol. 104, pp. 326-332, 2013.

[12] P. Ramachandran, C. Tsai, and G. W. Schanche, "An evaluation of coal water slurry fuel burners and Technology", USACERL Technical Report FE-93/09, Champaign, Il, USA, p. 108, 1992. 
[13] A. Zenkov, K. Larionov, and V. Gubin, "Review of coal-water fuel pulverization technology and atomization quality registration methods," MATEC Web of Conferences, vol. 110 01091, 2017.

[14] P. R. Choudhury, "Slurry fuels," Prog. Energy Combust. Sci., vol. 18 pp. 409-427, 1992.

[15] Y. Fan, H. Hu, L. Jin, S. Zhu, and Q. Zhang, "Static stability and rheological behavior of lignite char-water mixture," Fuel, vol. 104, pp. 7-13, 2013.

[16] A. Singh, A. H. Idrisi, and A. Kulshrestha, "Rheological behaviour of coal water slurries with and without additive," International Journal of Innovative Research in Science, Engineering and Technology, vol. 5, no. 10 , pp. 17643-48, 2016.

[17] T. Imam and S. Capareda, "Characterization of bio-oil, syn-gas and bio-char from switchgrass pyrolysis at various temperatures," Journal of Analytical and Applied Pyrolysis, vol. 93, pp. 170-177, 2012.

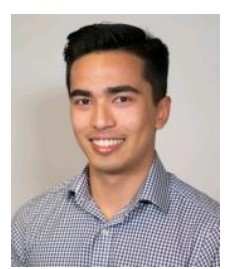

J. P. Pillai was born in Subang Jaya, Malaysia in 1993 He graduated from RMIT University in 2017 with a bachelor of engineering (chemical) (honours) and bachelor of business.

His research during his double degree particularly focused on the area of renewable energy and biofuels. During his studies, he has gained experience across several industries, completing internships in both Germany and Australia. Mr Pillai currently works at a consulting firm and continues to have an interest in the world of biofuels.

G. J. Griffin was born in Geelong, Australia in 1965. He graduated from the University of Melbourne with bachelors in engineering (chemical) and $\mathrm{PhD}$ in 1987 and 1993 respectively.

His research has, broadly, scanned heterogeneous reaction systems involving heat and mass transfer in such diverse areas as biomass utilisation, modelling of combustion and fire of materials, solvent extraction and copper electrowinning. He has been active in research on the conversion of lignocellulosic biomass to fuels or chemicals for over 20 years.

Dr Griffin has 38 journal and 28 conference papers in the fields of heterogeneous reactions with heat and mass transfer. He is currently senior lecturer and program manager in the School of Engineering at RMIT University, Melbourne, Australia.

M. Pannirselvam was born in India and has bachelors and masters of engineering degrees, as well as a $\mathrm{PhD}$ from RMIT University.

$\mathrm{He}$ has over five years of research experience (academic and industries), four years of process industrial experience, over five years of teaching experience (full time and part time between 2001 and 2014), and nine years of laboratory (academic and industries) management experience.

Dr Pannirselvam manages the Rheology and Materials Characterisation Laboratory at the School of Engineering in RMIT University. He is author and co-author of over 150 confidential industrial reports, is author and co-author of ten journal articles, over twenty five peer reviewed conference proceedings, a book chapter and co-editor of a book. He was involved and was part of team that has invented three products that are currently in market 